\title{
Clinical Significance of Decreased GPX1 Expression in Patients with Acute Myeloid Leukaemia (Non-M3)
}

\author{
Xiaolin Liang, Yibin Yao, Huiqun Li, Jie Wei, Chengyao Wan and Zhenfang Liu \\ Department of Hematology, The First Affiliated Hospital of Guangxi Medical University, Nanning, Guangxi, China
}

\begin{abstract}
Objective: To determine the expression levels of GPXI, SOCS5 and IL7 and their clinical significance in patients with acute myeloid leukaemia (AML).

Study Design: A case-control study.

Place and Duration of Study: Department of Hematology, The First Affiliated Hospital of Guangxi Medical University, Nanning, Guangxi, China, from January 2013 to November 2020.

Methodology: Based on the bioinformatics analysis, the expression levels of GPX1, SOCS5 and IL7 in the bone marrow of 64 AML patients (non-M3) and 32 healthy individuals were evaluated by real-time PCR. Correlation between GPXI expression and the clinical characteristics, response to induced chemotherapy, and survival time of AML patients were analysed as the outcome measure.

Results: GPXI was significantly downregulated in AML patients, which helped in distinguishing AML patients from normal controls. The area under the curve (AUC) of the receiver operator characteristic (ROC) was $0.741(p<0.001)$. Additionally, GPXI expression was correlated with gender $(r=-0.250, p=0.045)$, FAB classification $(r=-0.332, p=0.004)$, and chemotherapy response $(r=0.366, p=0.003)$. AML patients with high GPX1 expression levels had a lower rate of remission $(p=0.021)$ and poor long-term survival ( $p=0.036$ ) than those with low GPX1 expression levels.

Conclusion: Low GPX1 expression in AML patients may be closely associated with the pathogenesis and chemoresistance of AML.
\end{abstract}

Key Words: Acute myeloid leukaemia, Clinical outcome, Gene expression, GPX1.

How to cite this article: Liang X, Yao Y, Li H, Wei J, Wan C, Liu Z. Clinical Significance of Decreased GPX1 Expression in Patients with Acute Myeloid Leukaemia (Non-M3). J Coll Physicians Surg Pak 2021; 31(08):941-946.

\section{INTRODUCTION}

$\mathrm{AML}$ is a malignant clonal disease of the hematopoietic system that originates from myeloid hematopoietic stem/progenitor cells and presents enormous molecular heterogeneity. ${ }^{1}$ Recently, through the application of high-throughput microarray analysis, the role of AML in diagnosis, classification, outcome prediction and recognition of subsets has been understood. ${ }^{2}$ Gene expression profiling (GEP), which identifies differentially expressed genes (DEGs), has been widely applied. Some genes may provide prognostic forecasts and contribute to resistance to therapy, while acting as credible diagnostic biomarkers. ${ }^{1}$ Here, this study investigated novel potential biomarkers for the treatment and prognosis of AML.

Correspondence to: Dr. Zhenfang Liu, Department of Hematology, The First Affiliated Hospital of Guangxi Medical University, Nanning, Guangxi, China

E-mail: liuzhenfang@gxmu.edu.cn

Received: April 21, 2021; Revised: June 28, 2021;

Accepted: July 09, 2021

DOI: https://doi.org/10.29271/jcpsp.2021.08.941
Authors preparatory work identified several DEGs. Until now, the effects of GPXI or SOCS5 on the treatment and prognosis of AML patients has not been extensively studied. IL7 and SOCS5 are the activator and the profiling of the JAK/STAT pathway, respectively; however, the connection between these genes in the pathogenesis of AML remains unclear.

Glutathione peroxidase-1 (GPXI) is a member of the glutathione peroxidase (GPX) system that plays an important role of cellular oxidative metabolism. When cells are stimulated by oxidation, the transcription factor $N r f 1 / 2$, upregulates GPX1 expression, to reduce reactive oxygen species (ROS) generation. ${ }^{3}$ GPXI influences the progression of several tumours. Based on bioinformatics analysis, GPXI expression is upregulated in AML and myelodysplastic syndrome (MDS), ${ }^{4}$ and the high level of GPX1 expression is associated with poor clinical outcomes in AML. ${ }^{5,6}$ However, the role and mechanism underlying GPXI in AML remain to be elucidated.

Suppressor of cytokine signalling-5 (SOCS5) plays an important role in regulating gene, controlling bioprocesses such as growth and differentiation of cells and haematopoiesis, and immune function, mainly by suppressing the activation of the JAK/STAT signalling pathway. ${ }^{7}$ Abnormal expression and regulation of SOCS5 are involved in tumour genesis and progress. ${ }^{8}$ Interleuk- 
in-7 (IL7), an activator of the JAK/STAT pathway, is a growth factor for multi-effects that stimulates the development, proliferation and differentiation of $\mathrm{B}$ and $\mathrm{T}$ cells. ${ }^{9} \mathrm{~A}$ recent study demonstrated that IL7 is expressed at low levels in the peripheral blood of AML patients, ${ }^{10}$ whose level and function in the bone marrow (BM) of AMLare unclear.

To solve this problem, the aim of the present study was to explore these genes GPXI, SOCS5, and IL7 in the development, treatment, and prognosis of AML, which may provide a foundation for the development of novel therapeutic targets for AML treatment.

\section{METHODOLOGY}

In this study, 64 BM samples were obtained from patients with newly diagnosed AML before any chemotherapy between 2013-2016 in the Department of Hematology, The First Affiliated Hospital of Guangxi Medical University, China. Patients with other haematological diseases or malignant tumours were excluded, and all patients with AML were followed up regularly until November 2020. The diagnosis and subtypes of AML were established according to the WHO recommended criteria and FAB classification. The study was approved by the Human Ethics Committee of The First Affiliated Hospital of Guangxi Medical University, and all participants provided written informed consent according to the Declaration of Helsinki.

Identification of DEGs in AML and their prognostic value were performed using the ONCOMINE database. The protein-protein interaction (PPI) networks and hub genes were analysed using the Ssearch Tool for the Retrieval of Interacting Genes/Proteins (STRING) database to describe the biological relationship between genes, especially the PPI information. To analyse the DEGs at the functional level, the Kyoto Encyclopaedia of Genes and Genomes (KEGG) pathway enrichment analysis was performed using the Database for Annotation, Visualisation, and Integrated Discovery (DAVID). The results were considered statistically significant, when the $p$-values were $<0.05$.

BM samples ( $2 \mathrm{ml}$ ) were extracted from each subject, and BM mononuclear cells (BM-MNCs) were separated from the BM samples by density gradient centrifugation. According to the manufacturer's protocol, TRIzol reagent (Invitrogen, USA) was added to the samples for conservation in a $-80^{\circ} \mathrm{C}$ refrigerator until required for total RNA extraction. RNA concentration and purity were measured by ultraviolet spectrophotometric examination and agarose gel electrophoresis. Total RNA was reverse transcribed into cDNA. Sense and antisense primers for target genes were designed using Primer 5.0. The primers used for each gene were as follows: GPX1 forward 5'-CGCTGGCTTCTTGGACAAT-3' and reverse 5'-AGAAGGCATACACCGACTGG-3', IL7 forward 5'-AGGGTCCTGGGAGTGACTATGG-3' and reverse 5'-TGATGCTACTGGCAACAGAACAA-3', SOCS5 forward5'-CTCCCTCTACCCTCAATGTTAC-3' and reverse 5'-TTACTTTGCCTTGACTGGTTCT-3'. The housekeeping gene $\beta$-actin was used in PCR amplification as the internal reference to normalise the data, with the following primers: forward 5'-GTGGCCGAGGACTTI-
GATTG-3' and reverse 5'-CCTGTAACAACG CATCTCATATT-3'.

Real-time PCR was performed on RNA samples using the QuantStudio $^{\text {TM }} 5$ Real-Time PCR System (Applied Biosystems, USA). The Real-time PCR was carried out under the following conditions: $10 \mathrm{~min}$ at $95^{\circ} \mathrm{C}$, followed by 40 cycles of $10 \mathrm{~s}$ at $95^{\circ} \mathrm{C}$ and $60 \mathrm{~s}$ at $60^{\circ} \mathrm{C}$. Finally, melting was carried out between $60-99^{\circ} \mathrm{C}$ (with $0.5^{\circ} \mathrm{C}$ increments) for $5 \mathrm{~s}$ at each step. Besides, PCR product specificity was verified using a melting curve. The relative expression levels of GPXI, IL7, and SOCS5 were calculated using the comparative $2^{-\Delta \Delta c t}$ method.

All statistical analyses were performed using SPSS (version 23.0; SPSS Inc., Chicago, IL). Data were depicted by GraphPad Prism (version 8.0, Inc, La Jolla, CA, USA). Because the data did not meet the normal distribution, Mann-Whitney's U-test, Pearson Chisquare test, and Fisher's Exact probabilities were used to evaluate the difference in gene expression among different groups and the relationship between GPXI expression and clinical parameters. Quantitative variables are expressed as median (IQR) and qualitative variables are expressed as number and percentages. Pearson's correlation analysis was performed to evaluate the correlation between the two variables. Receiver operator characteristic (ROC) analysis was used to assess the sensitivity, specificity, and the area under the curve (AUC) of GPX1 expression. The Kaplan-Meier survival curve was used to examine the relationship between gene expression levels and clinical outcomes. Cox proportional hazards regression model analysis was applied to analyse the risk factors for AML patients with statistical significance in clinical prognosis. In the study, all comparisons were considered statistically significant at $P<0.05$.

\section{RESULTS}

First, DEGs of AML were analysed in the ONCOMINE database and identified a total of 15 genes (CUL5, IL7, IL7r, JAK2, STAT5A, STAT5b, ADAM28, TCEB1, SOCS5, IL2RG, GPX1, SOD1, SOD2, and $G S R$ ) that were most related to the clinical prognosis of $A M L$, and then two PPI networks and 14 hub genes were identified (Figure 1). KEGG enrichment analysis demonstrated that these DEGs were significantly enriched in the JAK/STAT signalling pathway (Table I). Considering the value of GPXI expression levels and that the relationship between SOCS5 and IL7 in AML remains undefined, the authors investigated the expression levels of these three genes in BM-MNCs and their clinical significance in AML.

The clinical characteristics of the patients are summarised in Table II. The control group consisted of 32 healthy volunteers and donors without cancer: 15 men and 17 women, with a median age of 32 years (range 24-47). The relative expression levels of GPXI, IL7 and SOCS5 in AML patients and normal controls were analysed using real-time PCR arrays, as shown in Figure 2A. GPX1 expression was significantly downregulated in AML patients compared to that in healthy individuals ( $p<0.001$; Figure 2B). The ROC curve showed that GPX1 is a potential indicator which could discriminate AML patients from normal subjects with an AUC of 0.741 ( $p<0.001,95 \%$ confidence interval $(\mathrm{Cl})$ : $0.636-0.845$, Figure $3 \mathrm{~A}$ ). There was no significant difference in 
the expression levels of IL7 and SOCS5 between patients and normal controls; therefore, authors herein focus on analysis of GPX1. Furthermore, significant differences were observed in the relative expression of GPX1 between different FAB classifications, specifically in $M 1$ and $M 5(p=0.039), M 2$ and $M 4(p=$ $0.007), M 2$ and M5 ( $p=0.018$; Figure $2 C)$. With the median expression of GPXI as the cut-off value, the patients were divided into a low expression group $(n=32)$ and a high expression group ( $\mathrm{n}=32$ ). The relationship between GPX1 expression and clinical characteristics is shown in Table I. GPXI expression wasassociated with gender $(r=-0.250, p=0.045), F A B$ classification $(r=-0.332, p=0.004)$, and chemotherapy response $(r=$ $0.366, p=0.003$ ) in AML patients.

Table I: KEGG pathway analysis of DEGs associated with AML.

\begin{tabular}{|c|c|c|c|}
\hline KEGG Term & Counts & $\mathbf{p}$ & Genes \\
\hline $\begin{array}{l}\text { aml04630: JAK/STAT signaling } \\
\text { pathway }\end{array}$ & 7 & 9.42E-09 & $\begin{array}{c}\text { IL7, STAT5A, } \\
\text { STAT5B, JAK2, } \\
\text { IL2RG, SOCS5, IL7R }\end{array}$ \\
\hline $\begin{array}{l}\text { aml04917: Prolactin signaling } \\
\text { pathway }\end{array}$ & 4 & $1.54 \mathrm{E}-04$ & $\begin{array}{l}\text { STAT5A, STAT5B, } \\
\text { JAK2, SOCS5 }\end{array}$ \\
\hline aml05162: Measles & 4 & $6.40 \mathrm{E}-04$ & $\begin{array}{l}\text { STAT5A, STAT5B, } \\
\text { JAK2, IL2RG }\end{array}$ \\
\hline $\begin{array}{l}\text { aml04151: PI3K-Akt signaling } \\
\text { pathway }\end{array}$ & 4 & 0.011893 & $\begin{array}{l}\text { IL7, JAK2, IL2RG, } \\
\text { IL7R }\end{array}$ \\
\hline $\begin{array}{l}\text { aml04060: Cytokine-cytokine } \\
\text { receptor interaction }\end{array}$ & 3 & 0.03085 & IL7, IL2RG, IL7R \\
\hline $\begin{array}{l}\text { aml05340: Primary } \\
\text { immunodeficiency }\end{array}$ & 2 & 0.046449 & IL2RG, IL7R \\
\hline aml05166: HTLV-I infection & 3 & 0.048462 & $\begin{array}{l}\text { STAT5A, STAT5B, } \\
\text { IL2RG }\end{array}$ \\
\hline
\end{tabular}

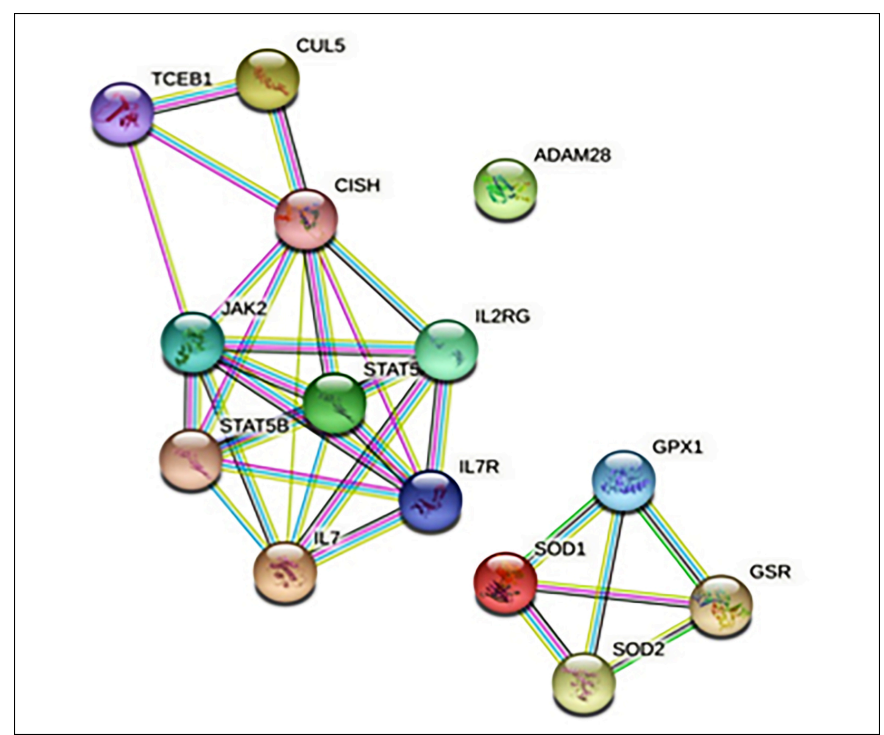

Figure 1: The protein-protein interaction networks and hub genes of DEGs.

According to the response to initial remission-induction chemotherapy, all patients were divided into two groups: those with complete remission (CR group, 43 cases) and those with no response (NR group, 21 cases). There was a significant difference in the relative expression level of GPXI between the two groups: patients in the CR group had a lower GPX1 expression than those in the NR group without remission $(p=0.021$; Figure 2D). Furthermore, to verify the effect on prognosis of GPX1 in
AML patients, the relationship between GPX1 expression and overall survival(OS) was assessed. The results showed that the high expression group was significantly different from the low expression group in OS ( $p=0.036$; Figure $3 B$ ), which suggested that GPX1 expression was associated with the survival of AML patients. However, GPX1 expression status did not persist as an OS predictor in the multivariate analysis (Table III).

Table II: Comparison of clinical and molecular characteristics with the expression of GPX1 in AML patients.

\begin{tabular}{|c|c|c|c|}
\hline \multirow{2}{*}{$\begin{array}{l}\text { Clinical } \\
\text { characteristics }\end{array}$} & \multicolumn{2}{|l|}{ GPX1 mRNA level } & \multirow{2}{*}{ p-value } \\
\hline & $\operatorname{Low}(n=32)$ & $\operatorname{High}(n=32)$ & \\
\hline $\begin{array}{l}\text { Age, years, } \\
\text { median(IQR) }\end{array}$ & $32.50(25.25-47.00)$ & $34.0(25.00-42.25)$ & 0.835 \\
\hline \multicolumn{3}{|c|}{ Age group, years, $\mathrm{n}(\%)$} & 0.599 \\
\hline$<40$ & $20(31.3)$ & $22(34.4)$ & \\
\hline$>40$ & $12(18.8)$ & $10(15.6)$ & \\
\hline \multicolumn{3}{|l|}{ Gender, n(\%) } & 0.045 \\
\hline Male & $11(17.2)$ & 19(29.7) & \\
\hline Female & $21(32.8)$ & $13(20.3)$ & \\
\hline $\begin{array}{l}\text { Hemoglobin, g/L, } \\
\text { median(IQR) }\end{array}$ & $75.6(65.0-88.7)$ & $72.5(63.4-82.7)$ & 0.489 \\
\hline $\begin{array}{l}\text { Leukocyte, } \times 10^{9} / \mathrm{L} \text {, } \\
\text { median(IQR) }\end{array}$ & $11.5(5.25-28.77)$ & 17.6(5.72-99.55) & 0.240 \\
\hline $\begin{array}{l}\text { Platelet, } \times 10^{9} / \mathrm{L} \text {, } \\
\text { median(IQR) }\end{array}$ & $49.8(23.58-78.40)$ & $33.0(18.08-87.45)$ & 0.277 \\
\hline $\begin{array}{l}\text { BM blasts ,\%, } \\
\text { median(IQR) }\end{array}$ & $52.2(39.75-67.25)$ & $59.0(37.25-72.75)$ & 0.428 \\
\hline \multicolumn{3}{|l|}{ FAB type, $\mathrm{n}(\%)$} & 0.004 \\
\hline M1 & $1(1.6)$ & $4(6.3)$ & \\
\hline M2 & $3(4.7)$ & $12(18.8)$ & \\
\hline M4 & $17(26.6)$ & 9(14.1) & \\
\hline M5 & $11(17.2)$ & $5(7.8)$ & \\
\hline M6 & $0(0)$ & $2(3.1)$ & \\
\hline \multicolumn{3}{|c|}{ Chromosome karyotype, $\mathrm{n}(\%)$} & 0.777 \\
\hline Normal & $24(37.5)$ & $23(35.9)$ & \\
\hline Abnormal & $8(12.5)$ & $9(14.1)$ & \\
\hline \multicolumn{3}{|c|}{ Mutation status, $\mathrm{n}(\%)$} & \\
\hline \multicolumn{3}{|l|}{ NPM1 } & 0.491 \\
\hline Mutation & $6(9.4)$ & $4(6.3)$ & \\
\hline Wild type & $26(40.6)$ & $28(43.8)$ & \\
\hline \multicolumn{3}{|l|}{ FLT3-IDT } & 0.474 \\
\hline Mutation & $3(4.7)$ & $6(9.4)$ & \\
\hline Wild type & $29(45.3)$ & $26(40.6)$ & \\
\hline C-kit & & & 0.613 \\
\hline Mutation & $1(1.6)$ & $3(4.7)$ & \\
\hline Wild type & $31(48.4)$ & $29(45.3)$ & \\
\hline \multicolumn{3}{|l|}{ DNMT3 } & 0.355 \\
\hline Mutation & $4(6.3)$ & 1(1.6) & \\
\hline Wild type & $28(43.8)$ & $31(48.4)$ & \\
\hline \multicolumn{3}{|l|}{ CEBPA } & 0.491 \\
\hline Mutation & $4(6.3)$ & $6(9.4)$ & \\
\hline Wild type & $28(43.8)$ & $26(40.6)$ & \\
\hline \multicolumn{3}{|c|}{ Hematopoietic stem cell transplantation (HSCT), n (\%) } & 0.226 \\
\hline Yes & $9(14.1)$ & $5(7.8)$ & \\
\hline No & $23(35.9)$ & $27(42.2)$ & \\
\hline \multicolumn{3}{|c|}{ Complete remission, $\mathrm{n}(\%)$} & 0.003 \\
\hline Yes & $27(42.2)$ & $16(25.0)$ & \\
\hline No & $5(7.8)$ & $16(25.0)$ & \\
\hline
\end{tabular}

Table III: Univariate and multivariate analyses in AML patients.

\begin{tabular}{|l|c|c|c|c|}
\hline \multirow{2}{*}{ Variables } & \multicolumn{2}{|c|}{ Univariate } & \multicolumn{2}{c|}{ Multivariate } \\
\cline { 2 - 5 } & HR(95\% CI) & $\mathbf{p}$ & HR(95\% CI) & $\mathbf{p}$ \\
\hline $\begin{array}{l}\text { GPX1 } \\
\text { (high vs. low) }\end{array}$ & $2.062(1.023-4.154)$ & $\mathbf{0 . 0 4 3}$ & $\begin{array}{c}1.394 \\
(0.674-2.883)\end{array}$ & 0.371 \\
\hline $\begin{array}{l}\text { Gender } \\
\text { (male vs. } \\
\text { female) }\end{array}$ & $0.591(0.297-1.176)$ & 0.134 & & \\
\hline
\end{tabular}




\begin{tabular}{|c|c|c|c|c|}
\hline $\begin{array}{l}\text { Age } \\
(<40 \text { vs. } \geq 40)\end{array}$ & $1.231(0.605-2.506)$ & 0.566 & & \\
\hline $\begin{array}{l}\text { Leukocyte } \\
\text { (<20 vs. } \\
\left.\geq 20 \times 10^{9} / \mathrm{L}\right)\end{array}$ & $0.898(0.441-1.829)$ & 0.768 & & \\
\hline $\begin{array}{l}\text { NPM1 } \\
\text { (mutated vs. } \\
\text { wild) }\end{array}$ & $2.327(0.709-7.637)$ & 0.164 & & \\
\hline $\begin{array}{l}\text { FLT3-ITD } \\
\text { (mutated vs. } \\
\text { wild) }\end{array}$ & $0.788(0.304-2.044)$ & 0.624 & & \\
\hline $\begin{array}{l}\text { C-kit } \\
\text { (mutated vs. } \\
\text { wild) }\end{array}$ & $0.989(0.236-4.149)$ & 0.987 & & \\
\hline $\begin{array}{l}\text { DNMT3 } \\
\text { (mutated vs. } \\
\text { wild) }\end{array}$ & $1.484(0.355-6.203)$ & 0.589 & & \\
\hline $\begin{array}{l}\text { CEBPA } \\
\text { (mutated vs. } \\
\text { wild) }\end{array}$ & $0.965(0.372-2.502)$ & 0.942 & & \\
\hline $\begin{array}{l}\text { BM blasts } \\
\text { (<60 vs. } \\
\geq 60 \% \text { ) }\end{array}$ & $1.652(0.833-3.277)$ & 0.151 & & \\
\hline $\begin{array}{l}\text { Complete } \\
\text { remission } \\
\text { (yes vs. no) }\end{array}$ & $0.170(0.083-0.348)$ & $<0.001$ & $\begin{array}{c}0.278 \\
(0.131-0.589)\end{array}$ & 0.001 \\
\hline $\begin{array}{l}\text { HSCT } \\
\text { (yes vs. no) }\end{array}$ & $0.070(0.010-0.513)$ & 0.009 & $\begin{array}{c}0.120 \\
(0.016-0.921)\end{array}$ & 0.041 \\
\hline
\end{tabular}

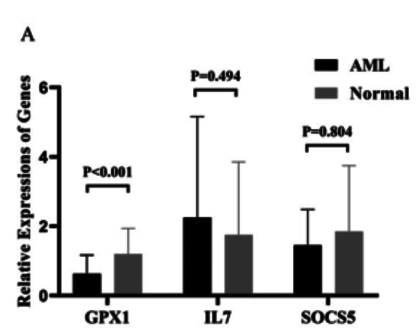

B

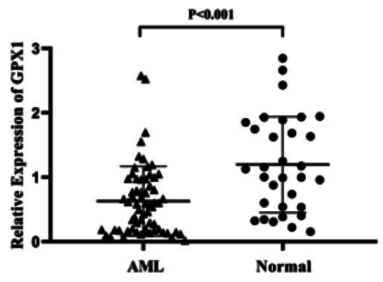

C

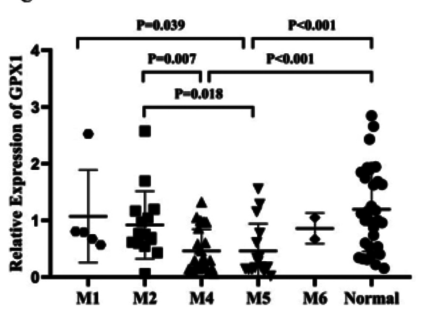

D

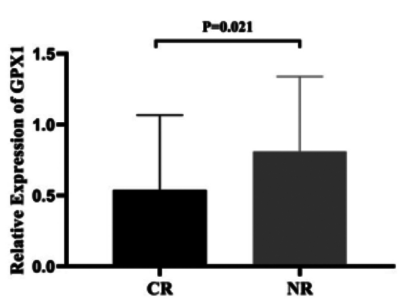

Figure 2: A. The relative expression levels of GPX1, IL7 and SOCS5 in AML patients and normal controls. B. The relative expression of GPX1 in AML group and normal controls. $C$. The relative expression of $G P X 1$ in each $F A B$ subgroup of AML patients and normal controls. D. Correlation between GPX1 relative expression and response to induction chemotherapy.

\section{DISCUSSION}

GPX1 is closely connected with the oxidative metabolism of cells, which degrades ROS levels under oxidative stress. ROS, which is tightly associated with the emergence, expansion, metastasis and survival of cancer patients, is mostly higher in cancer cellsthan in normalcells. ${ }^{11}$
A

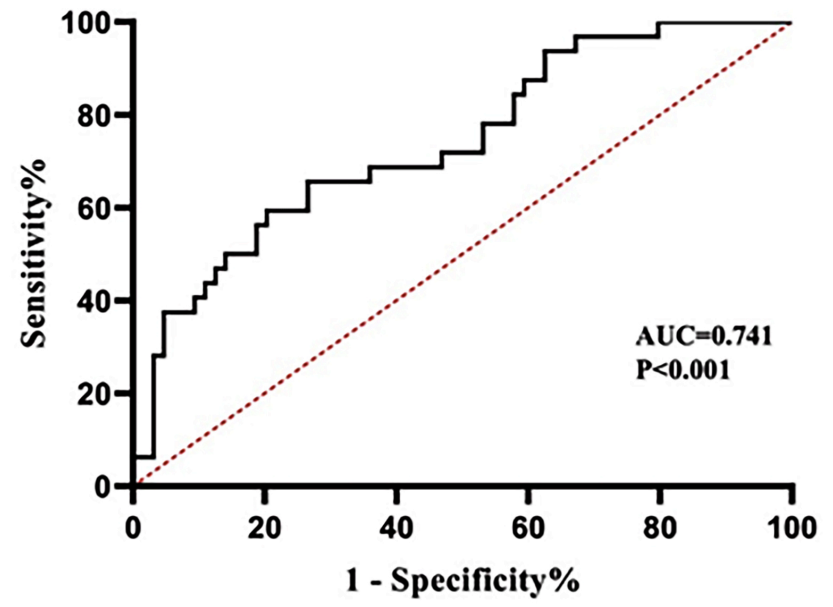

B

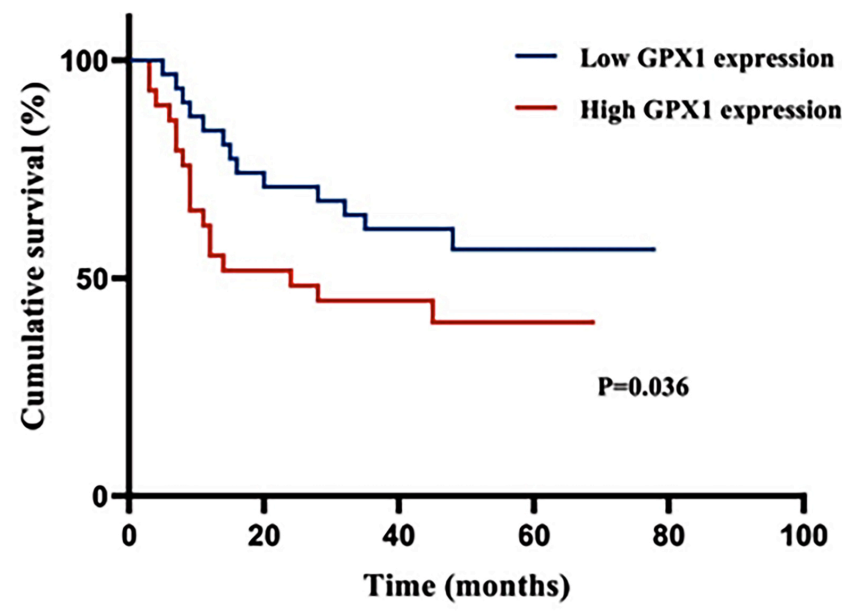

Figure 3: (A) ROC analysis using GPX1 for separating AML cases from normal controls. (B) Kaplan-Meier survival curves for AML patients which were divided into two groups based on the median value of GPX1 expressionlevel.

Accumulated evidence suggests that the expression levels of GPXI vary among different tumors. Cancers with high levels of GPX1 expression includes mainly squamous cell carcinoma, such as laryngeal squamous cell carcinoma and esophageal squamous cell carcinoma, ${ }^{12,13}$ while cancers with low GPX1 levels includes mainly glandular cell carcinoma, such as pancreatic cancer, breast cancerand gastric cancer. ${ }^{14-16}$

Bioinformatics analysis has previously shownthat GPX1 is upregulated in AML; however, large-scale clinical studies are needed to verify these conclusions. ${ }^{6}$ It is thought-provoking that authors observed a decrease in GPX1 mRNA expression in patients with AML, opposing the previous study as well as the result based on the ONCOMINE database, the authors analysed before. However, bioinformatics analysis only lays the foundation of this project, and the results may differ for each race, as well as the experimental results shall prevail. The authors speculate that AML cells generate less GPXI mRNA than normal cells due to promoter methylation of GPX1, as in gastric cancer, DNA promoter methylation correlates with the loss of GPXI expression. ${ }^{16}$ Furthermore, treatment with a methylation inhibitor increased the mRNA and 
protein levels of GPXI and enhanced the cell's antioxidant capacity, ${ }^{17}$ indicating that promoter methylation influences GPX1 expression.

There is abnormal DNA methylation in AML revealed by wholegenome DNA methylation sequencing, ${ }^{18}$ indicating a possible explanation for GPX1 down-regulation. Further experiments are required for the detection of GPX1 promoter methylation levels in $A M L$, to confirm the above conjecture. In summary, GPXI had a relatively low expression in $A M L$, which is partly consistent with a previous report. ${ }^{19}$ Rasool et al. suggested that GPXs were reduced in patients suffering from $A M L$, and low expression of GPX1 participated in the occurrence and development of AML. However, overexpression of GPX1 under induction to determine whether it can suppress the multiplication and promote apoptosis of AML cells is the next step the authors plan to do. Additionally, abnormal expression of GPX1 is associated with clinical features of cancers, including TNM staging and lymphatic metastasis. ${ }^{13,16}$ This study indicates that GPX1 expression has a connection with FAB classification. The authors speculate that different $F A B$ types may have diverse degrees of BM-MNC differentiation. Thus, the authors need more clinical specimens and cell experiments to verify the above thoughts, especially the samples of M1 and M6.

GPX1 plays a crucial role in tumour growth and chemoresistance. Some scholars believe that oxidative metabolic stress is involved in the relapse and drug resistance of $\mathrm{AML} .{ }^{20}$ Over $60 \%$ of AML cells could result in high levels of NOX-derived ROS, accelerating primary $\mathrm{AML}$ blast multiplication. ${ }^{21}$ In multidrug resistance of Burkittlymphoma cells, the production of ROS induces the phosphorylation of STAT3, which improves the expression of GPX1 and SOD2 to protect cells from oxidative stress. ${ }^{22}$ GPX1 is also upregulated in resistant B-cell lymphoma cells treated with cisplatin and methotrexate. ${ }^{23}$ The results showed that GPX1 expression in the NR group was significantly higher than that in the CR group. It is likely that AML patients in the CR group with a low expression of GPX1 may have increased ROS levels induced by chemotherapy, which exert synergistic combination with chemotherapeutic drugs to kill tumour cells together. Similarly, one study suggested that in the treatment of acute promyelocytic leukaemia, arsenic trioxide combined with ROS can accelerate the degradation of the PMLRARA oncoprotein. ${ }^{24}$ Despite evidence manifests that a high level of ROS stimulates the proliferation of tumour cells, a study verified that cytarabine and daunorubicin, the first-line therapyin theinduction chemotherapy of AML, could promote ROS acumulation and induce apoptosis in AML cells. ${ }^{25}$ Abnormal GPX1 expression in AML likely affects the efficacy of chemotherapy; hence, regulating its expression may contribute to the treatment of relapsed or refractory AML and become a novel therapeutic strategy for AML. Nevertheless, the relative expression of GPX1 in AML patients with refractory/relapse before and after standard treatment has not been reported. Further investigations on the role of GPXI in AML resistanceand its exact mechanisms are essential.

GPX1 is involved in the pathogenesis of many diseases, and its function varies with tumour type in the occurrence and progression of diseases. Authors preliminary work revealed that high expression of GPX1 suggested a poor prognosis, as analysed by the GEPIA database $(p=0.013)$, was consistent with current study. Similarly,
Wei et al. revealed that high GPX1 levels are related to adverse clinical outcomes and poor survival. ${ }^{6}$ A possible explanation could be that the reduced GPX1 expression and the accumulation of ROS led to leukaemia cell deaths, and the patients reached remission and had a better survival. On the other hand, chemotherapy-resistant AML patients tend to have increased GPX1, which leads to a shorter OS. Considering this findings, further studies in this area are necessary to gain insight into the role of GPX1 mRNA expression in the clinical outcome and chemotherapy resistance of haematological malignancies. Authors aimed to detect the level of GPX1 in BM and measure the activity of glutathione peroxidase and ROS levels in the peripheralblood ofAMLpatientsafterchemotherapy toconsummate above investigation. Since GPX1 expression is related to prognosis in some tumours, controlling its level may be a strategy to prolong the survival time of patients, which can be seen as a potential target for therapy in the future.

\section{CONCLUSION}

GPX1 expression in the bone marrow of AML patients is significantly downregulated compared to that in normal controls, and may play an important role in the diagnosis, pathogenesis, and chemoresistance of AML.

\section{FUNDING:}

This study was supported by grants from National Natural Science Foundation of China (No. 81560028) and Science Research and Technology Development Project of Qingxiu District of Nanning (No. 2020055).

\section{ETHICALAPPROVAL:}

This study was approved by the Human Ethics Committee of The First Affiliated Hospital of Guangxi Medical University, China. (2020(KY-E-147).

\section{PATIENTS' CONSENT:}

Informed consents were obtained from patients to publish the data concerning this case.

\section{CONFLICT OF INTEREST:}

The authors declared no conflict of interest.

\section{AUTHORS' CONTRIBUTION:}

$X L, Y Y, Z L$ : Designed the project.

$\mathrm{XL}, \mathrm{YY}, \mathrm{HL}$, JW, CW: Performed the experiment and analysed the data.

$X L, H L$, JW: Drafted the manuscript.

YY, CW, ZL: Approved the final version to be published.

\section{REFERENCES}

1. Dohner H, Weisdorf DJ, Bloomfield CD. Acute Myeloid Leukemia. N Engl J Med 2015; 373(12):1136-52. doi: 10.1056/NEJMra1406184.

2. David Grimwade PD, Torsten Haferlach MD. Geneexpression profiling in acute myeloid leukemia. New Eng J Med 2004; 350:1676-8.

3. Hernandez-Montes E, Pollard SE, Vauzour D, Jofre-Montseny L, Rota C, Rimbach G, et al. Activation of glutathione peroxidase via Nrf1 mediates genistein's protection against oxidative endothelial cell injury. Biochem Biophys Res 
Communications 2006; 346(3):851-9. doi: 10.1016/j.bbrc. 2006.05.197.

4. Zhang Z, Zhao L, Wei X, Guo Q, Zhu X, Wei R, et al. Integrated bioinformatic analysis of microarray data reveals shared gene signature between MDS and AML. Oncol Lett 2018; 16(4): :5147-59. doi: 10.3892/ol. 2018.9237.

5. Wei R, Qiu H, Xu J, Mo J, Liu Y, Gui Y, et al. Expression and prognostic potential of GPX1 in human cancers based on data mining. Ann Transl Med 2020; 8(4):124. doi: 10.21037/atm.2020.02.36.

6. Wei J, Xie Q, Liu X, Wan C, Wu W, Fang K, et al. Identification the prognostic value of glutathione peroxidases expression levels in acute myeloid leukemia. Ann Transl Med 2020; 8(11):678. doi: 10.21037/atm- 20-3296.

7. Morita $Y$, Kawazoe $Y$, Fujimoto M, Narazaki M, Nakagawa R, Fukuyama $H$, et al. Signals transducers and activators of transcription (STAT)-induced STAT inhibitor-1 (SSI-1)/suppressor of cytokine signaling-1 (SOCS-1) suppresses tumor necrosis factor $\alpha$-induced cell death in fibroblasts. Proc Natl Acad Sci USA 2000; 97(10):5405-10. doi: 10.1073/pnas.090084797.

8. Mengqi Yang HC, Zhou L, Huang X, Su F, Wang P. Identification of SOCS family members with prognostic values in human ovarian cancer. Am J Transl Res 2020; 12(5):1824-38. eCollection 2020.

9. Touw I, Agthoven TV, Gurp RV, Budel L, Hoogerbrugge H, Delwel $R$, et al. Interleukin-7 is a growth factor of precursor $B$ and $T$ acute lymphoblastic leukemia. Blood 1990; 75(11):2097-101.

10. Li ZH, Liu Y, SY G. Correlation between IL-7 genomic protein methylation level and acute myeloid leukemia. Eur Rev Med Pharmacol Sci 2019; 23(3):1196-202. doi: 10.26355/eurrev_201902_17012.

11. Tong L, Chuang CC, Wu S, Zuo L. Reactive oxygen species in redox cancer therapy. Cancer Lett 2015; 367(1):18-25. doi: 10.1016/j.canlet.2015.07.008.

12. Xiangfeng Gan ZH, Chen B, Chen J. High GPX1 expression promotes esophageal squamous cell carcinoma invasion, migration, proliferation and cisplatin-resistance but can be reduced by vitamin D. Int J Clin Exp Med 2014; 7(9):2530-40. eCollection 2014.

13. Zhang Q, Xu H, You Y, Zhang J, Chen R. High Gpx1 expression predicts poor survival in laryngeal squamous cell carcinoma. Auris Nasus Larynx 2018; 45(1):13-9. doi: 10.1016/j.anl.2017.05.012.

14. Krol MB, Galicki M, Gresner P, Wieczorek E, Jablonska E, Reszka E, et al. The ESRI and GPXI gene expression level in human malignant and non-malignant breast tissues. Acta Biochim Pol 2018; 65(1):51-7. doi: 10.18388/abp.2016_ 1425.

15. Meng Q, Xu J, Liang C, Liu J, Hua J, Zhang Y, et al. GPx1 is involved in the induction of protective autophagy in pancreatic cancer cells in response to glucose deprivation. Cell Death Dis 2018; 9(12):1187. doi: 10.1038/s41419018-1244-z.

16. Sun Young Min HSK, Jung EJ, Ji Jung E, Do Jee C, Ho Kim W. Prognostic significance of glutathione peroxidase 1 (GPX1) down-regulation and correlation with aberrant promoter methylation in human gastric cancer. Anticancer Res 2012; 32:3169-75.

17. Kulak MV, Cyr AR, Woodfield GW, Bogachek M, Spanheimer PM, Li T, et al. Transcriptional regulation of the GPX1 gene by TFAP2C and aberrant CpG methylation in human breast cancer. Oncogene 2013; 32(34):4043-51. doi: 10.1038/onc.2012.400.

18. Timothy J, Ley CM, Ding L. Genomic and epigenomic landscapes of adult De Novo acute myeloid leukemia. New Engl J Med 2013; 368(22):2059-74. doi: 10.1056/ NEJMoa1301689.

19. Rasool M, Farooq S, Malik A, Shaukat A, Manan A, Asif M, et al. Assessment of circulating biochemical markers and antioxidative status in acute lymphoblastic leukemia (ALL) and acute myeloid leukemia (AML) patients. Saudi J Biol Sci 2015; 22(1):106-11. doi: 10.1016/j.sjbs.2014.09.002.

20. Sriskanthadevan S, Jeyaraju DV, Chung TE, Prabha S, Xu W, Skrtic M. AML cells have low spare reserve capacity in their respiratory chain that renders them susceptible to oxidative metabolic stress. Blood 2015; 125(13):2120-30. doi: 10.1182/blood-2014-08-594408.

21. Hole PS, Zabkiewicz J, Munje C, Newton Z, Pearn L, White P, et al. Overproduction of NOX-derived ROS in AML promotes proliferation and is associated with defective oxidative stress signaling. Blood 2013; 122(19):3322-30. doi: 10.1182/blood-2013-04-491944.

22. Zeng R, Tang Y, Zhou H, Liu Y, Huang J, Li L, et al. STAT3 mediates multidrug resistance of Burkitt lymphoma cells by promoting antioxidant feedback. Bioch Biophy Res Communications 2017; 488(1):182-8. doi: 10.1016/ j.bbrc.2017.05.031.

23. Schulz R, Emmrich T, Lemmerhirt H, Leffler U, Sydow K, Hirt $C$, et al. Identification of a glutathione peroxidase inhibitor that reverses resistance to anticancer drugs in human Bcell lymphoma cell lines. Bioorganic Med Chemis Lett 2012; 22(21):6712-5. doi: 10.1016/j.bmcl.2012.08.091.

24. Jeanne M, Lallemand-Breitenbach V, Ferhi O, Koken M, Le Bras M, Duffort $S$, et al. PML/RARA oxidation and arsenic binding initiate the antileukemia response of As203. Cancer Cell 2010; 18(1):88-98. doi: 10.1016/j.ccr. 2010.06.003.

25. Sally-Anne Heasman LZ, Kristian M. Bowles, A. Rushworth S, David J. MacEwan. Protection of acute myeloid leukaemia cells from apoptosis induced by front-line chemotherapeutics is mediated by haem oxygenase- 1 . Oncotarget 2011; 2(9):658-68. doi: 10.18632/onco target. 321 . 